\title{
Penggunaan Alga Gel (Nataclhorella) Dalam Larva Rearing Untuk Meningkatkan Survival Rate Benih Kerapu Sunu (Plectropomus leopardus)
}

\section{Use Of Alga Gel (Nataclhorella) Rearing Larva In Survival Rate Increase For Coral Trout Grouper (Plectropomus leopardus)}

\author{
*Irawati dan Damaris Payung \\ Politeknik Kelautan dan Perikanan Maluku, \\ Jl. Laksdya Leo Wattimena No.KM, RW.16, Waiheru, Baguala, Kota Ambon, Maluku \\ *e-mail korespondensi : irawatimuhidin@gmail.com
}

\begin{abstract}
Conditions Ambon Island are often rainy unfavorable impact for seeding activities in BBL-Ambon. This is due to the development of phytoplankton which is the natural food for larval growth and seed is not optimal and death. Limited availability of phytoplankton can cause failure in the overall seeding activities. This is because the function of phytoplankton is very vital for the survival of larvae. Phytoplankton than zooplankton also serves as a food stabilizing water quality maintenance media. Natachlorella is one product of phytoplankton species Chlorella compacted in the form of a gel. Its use is now growing in the hatchery installation during wet weather conditions and low solar intensity. Natachlorela use in coral trout grouper hatchery has not been done, this is because the development of coral trout grouper hatchery undeveloped optimal. For that the coral trout grouper hatchery activities in rainy conditions using the BBL-Ambon natachlorela dissolved in maintenance medium. The activities carried out during the spawning cycles of 3 months from October to December 2013. Giving plankton (natadechlorella sp) done in larvae aged D2 1 time a day and are given at the time of the morning. When the larvae mature D3 - D25 plankton given 2 times a day (morning and afternoon), with dosage $20 \mathrm{ml} / 10$ tons of sea water. Results obtained from 3-month spawning cycle is 1020 coral trout grouper fry (P. leopardus) size of $3 \mathrm{~cm}$.
\end{abstract}

Keywords : Algae gel, larval rearing, survival rate, coral trout grouper

\begin{abstract}
Abstrak. Kondisi Pulau Ambon yang sering hujan memberikan dampak yang kurang menguntungkan bagi kegiatan pembenihan di BBL-Ambon. Hal ini disebabkan perkembangan fitoplankton yang merupakan makanan alami bagi pertumbuhan larva dan benih tidak optimal dan mengalami kematian. Keterbatasan ketersediaan fitoplankton dapat menyebabkan kegagalan dalam kegiatan pembenihan secara keseluruhan. Ini karena fungsi dari fitoplankton sangat vital bagi kelangsungan hidup larva. Fitoplankton selain berfungsi sebagai makanan zooplankton juga menstabilkan kualitas air media pemeliharaan. Natachlorella merupakan salah produk dari fitoplankton yang dipadatkan dari jenis Chlorella dalam bentuk gel. Penggunaannya kini semakin berkembang di instalasi pembenihan pada saat kondisi musim hujan dan intensitas matahari rendah. Penggunaan natachlorela dalam pembenihan kerapu sunu belum pernah dilakukan, ini karena perkembangan pembenihan kerapu sunu yang belum berkembang optimal. Untuk itu dalam kegiatan pembenihan kerapu sunu dalam kondisi hujan BBL-Ambon menggunakan natachlorela yang dilarutkan dalam media pemeliharaan. Kegiatan ini dilakukan selama 3 siklus pemijahan dari bulan Oktober Desember 2012. Pemberian plankton (natadechlorella sp) dilakukan pada umur larva D2 sebanyak 1 kali sehari dan diberikan pada waktu pagi hari. Ketika larva berumur D3 - D25 plankton diberikan 2 kali sehari (pagi dan sore), dengan dosisi 20 ml/10 ton air laut. Hasil yang diperoleh dari 3 bulan siklus pemijahan adalah 1020 ekor benih kerapu sunu (P. leopardus) ukuran $3 \mathrm{~cm}$. Kata Kunci : Alga gel, larva rearing, survival rate, kerapu sunu
\end{abstract}

\section{PENDAHULUAN}

Usaha budidaya/pembesaran ikan kerapu sunu ( $P$. leopardus) di Indonesia belum berkembang dengan baik seperti halnya jenis kerapu yang lain. Hal ini disebabkan pasokan benih untuk kegiatan pembesaran masih sangat terbatas dan umumnya masih bergantung pada benih hasil tangkapan nelayan di alam. Akibat kegiatan eksploitasi dari tahun ke tahun yang terus meningkat, maka di beberapa daerah di Indonesia sudah ada indikasi terjadi over eksploitasi (kelebihan tangkap). Untuk menjawab permasalahan ini maka perlu upaya pembenihan secara berkesinambungan.

Pembenihan ikan kerapu sunu di Indonesia masih terbatas pada beberapa daerah tertentu antara lain Bali dan lampung. Sementara di Ambon khususnya Balai Budidaya Laut Ambon kegiatan pembenihan komoditas ini mulai dilakukan pada tahun 2008 yang terlebih dahulu dilakukan kegiatan domestikasi induk tahun 2007. Dari dua kegiatan tersebut telah mampu menghasilkan induk-induk matang gonad akan tetapi pemijahan induk belum terjadi sepanjang tahun. Kegiatan larva rearing juga dilakukan meskipun larva hanya mampu bertahan hidup sampai umur 8 hari.

Pada tahun 2009 kegiatan pembenihan kerapu sunu terus digalakan dan dari kegiatan ini juga menghasilkan induk-induk matang gonad dengan pemijahan yang terjadi sepanjang tahun. Kegiatan larva rearing sudah berjalan dengan baik dan mampu menghasilkan benih kerapu sunu. Dan di Tahun 2011 BBL-Ambon sudah bisa 
mengahsilkan benih kerapu sunu walaupun sintasan (SR) benih kerapu sunu yang dihasilkan masih tergolong cukup rendah.

Kondisi Pulau Ambon yang sering hujan memberikan dampak yang kurang menguntungkan bagi kegiatan pembenihan di BBL-Ambon. Hal ini disebabkan perkembangan fitoplankton yang merupakan makanan alami bagi pertumbuhan larva dan benih tidak optimal dan mengalami kematian. Keterbatasan ketersediaan fitoplankton dapat menyebabkan kegagalan dalam kegiatan pembenihan secara keseluruhan. Ini karena fungsi dari fitoplankton sangat vital bagi kelangsungan hidup larva. Fitoplankton selain berfungsi sebagai makanan zooplankton juga menstabilkan kualitas air media pemeliharaan.

Perkembangan budidaya fitoplankton dewasa ini telah sampai pada tingkatan menghasilkan produk fitoplankton yang dipadatkan dalam bentuk kering ataupun gel. Produk ini dihasilkan dari kelebihan produksi fitoplankton yang akan digunakan pada saat kondisi iklim yang ekstrim atau sering hujan sehingga kegiatan budidaya fitoplankton tidak bisa dilakukan.

Natachlorella merupakan salah produk dari fitoplankton yang dipadatkan dari jenis Chlorella dalam bentuk gel. Penggunaannya kini semakin berkembang di instalasi pembenihan pada saat kondisi musim hujan dan intensitas matahari rendah.

Penggunaan natachlorela dalam pembenihan kerapu sunu belum pernah dilakukan, ini karena perkembangan pembenihan kerapu sunu yang belum berkembang optimal. Untuk itu dalam kegiatan pembenihan kerapu sunu dalam kondisi hujan BBL-Ambon menggunakan natachlorela yang dilarutkan dalam media pemeliharaan.

Adapun tujuan dilakukan kegiatan ini adalah: penggunaan natachlorella dalam larva rearing kerapu sunu untuk meningkatkan SR larva kerapu sunu.

\title{
Waktu dan Tempat
}

\section{METODOLOGI PENELITIAN}

Kegiatan pemanfaatan natachlorela dalam larva rearing kerapu sunu untuk meningkatkan SR larva kerapu sunu, dilakukan di Indoor Hatchery Ikan Hias Balai Buiddaya Laut Ambon, dari dari bulan Oktober -Desember 2020.

\author{
Alat dan Bahan \\ a. Alat \\ Peralatan yang digunakan dalam kegiatan ini antara lain : \\ - Peralatan aerasi (Kran, Batu, pemberat, slang dan instalasinya) \\ - Selang kanvas diameter $3 / 4$ " \\ - Scop net telur \\ - Peralatan kerja (Ember, gayung, dan lain-lain) \\ - Bak larva (Kapasitas $10 \mathrm{~m}^{3}$ ) \\ - Aquarium (kapasitas 100 liter)
}

\section{b. Bahan}

Bahan-bahan yang digunakan dalam kegiatan ini adalah :

- Telur kerapu sunu

$\begin{array}{ll}- & \text { Natadechlorella gel } \\ - & \text { Rotifer } \\ - & \text { Pellet larva } \\ - & \text { Pellet benih } \\ - & \text { Artemia } \\ - & \text { Enrichment } \\ - & \text { Vitamin } \\ - & \text { Minyak cumi/ikan }\end{array}$

\section{Prosedur Kerja \\ Penanganan Telur Ikan Kerapu Sunu}

Panen telur dilakukan dengan cara mengalirkan air dari bak pemijahan ke dalam saringan panen (kolektor) telur berukuran 400 mikron yang dipasang pada bak panen telur, setelah telur terkumpul, kemudian telur dipanen dengan menggunakan scop net telur yang berukuran 300 - 400 mikron dan dimasukan kedalam wadah akuarium untuk diseleksi.

Seleksi telur dilakukan dengan cara mengangkat aerasi selama \pm 5 menit. Telur yang terbuahi berwarna bening dan transparan, melayang atau mengapung di permukaan air. Telur hasil pemijahan yang akan ditetaskan harus dipisahkan terlebih dahulu dari kotoran dengan menggunakan saringan berukuran $1 \mathrm{~mm}$. Setelah itu telur didiamkan agar supaya antara telur yang terbuahi dan yang tidak terbuahi akan segera terpisah. Telur yang tidak terbuahi akan 
mengendap pada dasar wadah akuarium bersama dengan partikel kotoran dan selanjutnya telur dan kotoran yang mengendap dikeluarkan dari dalam wadah aquarium dengan cara disipon. Total jumlah telur hasil panen dihitung dengan metode Volumetrik yaitu rerata telur hasil sampling (butir/ml) dikalikan dengan vulome akuarium (ml).

\section{Pemeliharaan Larva}

\section{Pengelolaan Bak dan Penebaran Telur}

* Bak yang digunakan untuk kegiatan ini berkapasitas $10 \mathrm{~m}^{3}$. Sebelum bak digunakan, terlebih dulu disterilkan dengan menggunakan kaporit dosis $80-100$ ppm dan dibilas dengan air tawar. Volume awal media pemelihaaran $4 \mathrm{~m}^{3}$.

* Padat penebaran telur didalam bak larva berkisar antara 5000 - $10000 \mathrm{butir} / \mathrm{m}^{3}$

* Saat larva kerapu baru menetas, dihitung hatching rate dengan cara pengambilan sampel dilakukan secara vertikal dengan pipa PVC berdiameter 1,5 - 2 inchi dengan panjang 1-1,3 m dan dilakukan sebanyak 5 kali pada titik yang berbeda, kemudian volume air dan jumlah larva dihitung dan selanjut dapat dihitung jumlah total larva di dalam bak.

* Setelah telur menetas pada permukaan air bak pemeliharaan ditetesi minyak cumi sebanyak $0,1 \mathrm{ml} / \mathrm{m}^{2}$ dan diberikan 2 kali sehari sampai larva berumur 10 hari, ketika larva berumur D2 diberikan probiotik sebanyak 10 - 20 ppm setiap hari atau antibiotik (0,5 - 1 ppm).

\section{Pengelolaan Pakan}

* Pakan alami yang biasanya digunakan dalam pemeliharaan larva kerapu sunu yaitu : rotifer, copepoda dan artemia. Rotifera diberikan pada umur larva D2 sebanyak 3 - 5 individu/ml pada sore hari, pada umur larva D30 diberikan 3 kali dalam sehari (pagi, siang, sore). Sebelum pemberian rotifera dilakukan pengkayaan pakan (scout emultion dan develop) atau ditambahkan vitamin C dan B complex powder dengan cara perendaman selama 2 - 6 jam. Selain rotifera, saat larva berumur 2 hari juga diberikan copepoda (berukuran 30 mikron) dengan kepadatan 5 - $7 \mathrm{ind} / \mathrm{ml}$. Nauplii artemia diberikan sebanyak 1-3 indiv/ml pada larva berumur D17 - D20 hanya 2 kali sehari, larva berumur D21 - D30 diberikan 2-3 kali sehari dan larva berumur D31 - D45 diberikan 3 kali sehari sebanyak 3 - 10 indiv/ml. Sebelum nauplii artemia diberikan dilakukan pengkayaan dengan menggunakan develop/selco.

* Pakan buatan (mikro pellet) diberikan ketika larva berumur D8 - D45 dan diberikan 2 - 6 kali sehari.

* Natachlorella diberikan $20 \mathrm{ml} / 10$ ton air laut dua hari sekali sampai larva berumur 25 hari

\section{Pengelolaan Sistem Aerasi dan Kualitas Air}

* Sistem Aerasi (pengudaraan) didalam bak larva dilakukan dengan menggunakan selang dan batu aerasi yang diletakan $5 \mathrm{~cm}$ diatas dasar bak pemeliharaan larva. Pada larva berumur 0 - 2, aerasi diberikan agak kuat untuk menghindari larva mengendap di dasar bak. Antara umur 3 -10, kecepatan aerasi dikurangi sampai kecepatan sedang. Antara umur 11 - 25, kecepatan aerasi ditambah sedikit demi sedikit dan larva berumur lebih dari 25 aerasi diperkuat.

* Pengelolaan kualitas air dilakukan dengan cara mempertahankan media pemeliharan sesuai standar yang telah ditetapkan, dengan cara pergantian air, pengaturan suhu dan kadar garam, penambahan plankton, pembersihan dinding dan dasar bak, penyebaran minyak cumi/ikan pada permukan air, pembersihan permukaan air dan mempertahankan warna air dalam bak larva. Pergantian air media pemeliharaan dilakukan ketika larva berumur 8 - 10 hari (D8 - D10) sebanyak 5-10\%/hari, pada umur larva D12 - D17 pergantian air sebanyak 20 - $30 \%$ /hari, pada umur larva D18 - D25, pergantian air sebanyak 30-40\%/hari, pada umur larva D26 D40, pergantian air sebanyak 40-50 \%/hari, dan pada umur larva > D45 pergantian air sebanyak $100 \%$ atau dengan sistem air mengalir. Agar kualitas air tetap terjaga, jika ada telur yang mengendap maka perlu dilakukan penyiponan dasar bak ketika larva baru berumur D1 (baru menetas). Setelah itu penyimponan dilakukan pada saat larva berumur D11 dan dilakukan secara hati-hati atau penyiponan dilakukan dengan melihat kondisi larva dan bak pemeliharaan (kotoran, lapisan minyak dan sisa pakan buatan dibuang dengan menggunakan gayung). Pada malam hari dilakukan penutupan bak dengan plastik transparan. Dalam pemeliharaan larva untuk menjaga stabilitas air dan menekan pertumbuhan populasi bakteri maka diberikan probiotik dosis $10-20 \mathrm{ppm}$ atau antibiotik berupa elbaju/erubazu dengan dosis $0,5-1 \mathrm{ppm}$.

* Pemberian plankton (natadechlorella sp) dilakukan pada umur larva D2 sebanyak 1 kali sehari dan diberikan pada waktu pagi hari. Ketika larva berumur D3 - D25 plankton diberikan 2 kali sehari (pagi dan sore), dengan dosis $20 \mathrm{ml} / 10$ ton air laut.

* Panen juvenil dilakukan pada saat larva berumur D35 atau D45, dan selanjutnya Juvenil hasil panen tersebut diseleksi ukurannya. 


\section{Analisa Data}

- Fertilization Rate (FR) :

$$
F R=\frac{\text { Jumlah Telur Terbuahi }}{\text { Tot.Jumlah Telur dalam bak }} x 100 \%
$$

- Hatching Rate (HR) :

$$
H R=\frac{\text { Jumlah telur menetas }}{\text { Jumlah telur keseluruhan }} \times 100 \%
$$

- Tingkat kelangsungan hidup (survival rate) :

$$
\begin{aligned}
& \text { - } \quad \text { SR Larva } \\
& \quad S R=\frac{\text { Jumlah larva akhir }}{\text { Jumlah larva awal }} \times 100 \%
\end{aligned}
$$

Selain itu dilakukan pula pengukuran kualitas air berupa kandungan oksigen terlarut, salinitas, pH, suhu, Ammoniak dan nitrit.

\section{HASIL DAN PEMBAHASAN}

\section{Ukuran Diameter Telur, Oil Globule, Derajat Pembuahan (FR) dan Derajat Penetasan (HR) Telur}

Selama kegiatan berlangsung, dari 3 siklus bulan pemijahan induk kerapu Sunu, ukuran diameter telur berkisar antara $700-830$ mikron, dengan diameter oil globule berkisar antara $150-170$ mikron. Untuk jelasnya dapat dilihat pada tabel berikut ini :

Tabel 1. Ukuran Diameter Telur dan oil globule Telur Kerapu Sunu Selama 3 Siklus Bulan Pemijahan

\begin{tabular}{lcc}
\hline \multirow{2}{*}{ Bulan } & Diameter Telur & Diameter Kuning Telur \\
\cline { 2 - 3 } & $(\boldsymbol{\mu m})$ & $(\boldsymbol{\mu m})$ \\
\hline Oktober & $700-830$ & $150-170$ \\
November & $700-830$ & $160-170$ \\
Desember & $700-830$ & $150-170$ \\
\hline
\end{tabular}

Ukuran diameter telur dan diameter kuning telur ini hampir sama dengan yang diperoleh oleh Amiruddin, $d k k$, (2011), yang memperoleh ukuran diameter telur kerapu sunu berkisar antara 700 - 840 mikron dan diameter kuning telur 150 - 170 mikron. Kesamaan ini diduga berasal dari penanganan induk kerapu yang sama, dimana sama-sama menggunakan pakan rucah dan pakan cumi yang sama serta pemberian suplemen vitamin dan mineral yang sama pula. Blaxter (1969) menyatakan bahwa kualitas telur ikan tergantung dari kualitas dan gizi pakan yang diberikan pada induk ikan. Hal senada dikatakan oleh Watanabe (1988) bahwa kuantitas dan kualitas pakan (protein dan lemak) yang diberikan kepada induk merupakan faktor penting yang mempunyai hubungan erat dengan kematangan gonad, jumlah telur yang diproduksi dan kualitas telur.

Pada setiap siklus pemijahan, derajat pembuahan telur (FR) dan derajat penetesan telur (HR) telur ikan kerapu Sunu selama kegiatan digolongkan cukup tinggi dimana Laju Pembuahan telur (FR) berkisar antara 75-80 \% sedang Laju Penetasan telur (HR) berkisar antara 80-90 \% (Tabel 2). Hasil ini sedikit berbeda dengan yang diperoleh oleh Amiruddin, $d k k$. (2011). Amiruddin, $d k k$., (2011) memperoleh laju fertilisasi dan laju penetasan telur kerapu sunu berkisar antara 70-85\% (FR) dan 79-93\% untuk HR. Walaupun kualitas pakan induk yang diberikan sama, namun derajat pembuahan dan derajat penetasan telur bisa berbeda. Ini diduga disebabkan oleh kualitas air media penetasan yang digunakan berbeda (suhu air waktu penetasan). Geffen et al., (2006) menyatakan bahwa peningkatan suhu air selama masa penetasan dapat meningkatkan mortalitas telur. Kemudian Laevastu dan Murray (1981) menyatakan bahwa suhu yang rendah membuat waktu inkubasi telur menjadi lambat, sedangkan suhu yang tinggi waktu inkubasi menjadi cepat. Lebih lanjut Tang dan Affandi (2000) menyatakan bahwa pada suhu tinggi proses metabolisme berjalan lebih cepat sehingga mempercepat proses penetasan, namun suhu yang terlalu tinggi atau terlalu rendah dapat menghambat proses penetasan, bahkan suhu yang terlalu ekstrim dapat menyebabkan kematian embrio dan kegagalan penetasan. 
Irawati dan Damaris Payung. Penggunaan Alga Gel (Nataclhorella) Dalam Larva Rearing Untuk Meningkatkan Survival Rate Benih Kerapu Sunu (Plectropomus leopardus)

Tabel 2. Derajat Pembuahan Telur (FR) dan Derajat Penetasan Telur (HR) Telur Selama 3 Siklus Pemijahan

\begin{tabular}{lcc}
\hline \multirow{2}{*}{ Bulan } & Fertilization Rate (FR) & Hatching Rate (HR) \\
\cline { 2 - 3 } & $\mathbf{( \% )}$ & $(\boldsymbol{\%})$ \\
\hline Oktober & $75-80$ & $80-90$ \\
November & $75-80$ & $80-90$ \\
Desember & $75-80$ & $80-90$ \\
\hline
\end{tabular}

\section{Produksi Benih}

Upaya produksi benih terus dilakukan melalui kegiatan pemeliharaan larva (larva rearing) kerapu Sunu yang dilakukan mulai bulan Oktober - Desember 2012 dengan menggunakan alga gel (natadechlorella) dan keberhasilan pemeliharaan larva kerapu sunu selama kegiatan berlangsung dapat dilihat pada tabel dibawah ini :

Tabel 3. Kelulusan Hidup Larva Kerapu Sunu (P. Leopardus) Selama 3 Siklus Pemijahan

\begin{tabular}{|c|c|c|c|c|c|}
\hline Bulan & $\begin{array}{c}\text { Kap. Bak } \\
\left(\mathbf{m}^{\mathbf{3}}\right) \\
\end{array}$ & $\begin{array}{c}\text { Jml Bak } \\
\text { (unit) } \\
\end{array}$ & $\begin{array}{c}\text { Padat } \\
\text { Tebar } \\
\text { (butir) }\end{array}$ & $\begin{array}{c}\text { Total Tebar } \\
\text { (butir) }\end{array}$ & $\begin{array}{c}\text { Keterangan } \\
\text { (Keberhasilan) }\end{array}$ \\
\hline \multirow[t]{2}{*}{ Okt } & 6 & 1 & 50000 & 50000 & Drop Umur 9 hari (D9) \\
\hline & 30 & 3 & 300000 & 900000 & Drop Umur 12hari (D12) \\
\hline \multirow[t]{2}{*}{ Nov } & 6 & 2 & 50000 & 100000 & Sampai panen umur 1020 ekor \\
\hline & 30 & 3 & 300000 & 900000 & Drop Umur 23 hari (D23) \\
\hline \multirow[t]{2}{*}{ Des } & 6 & 2 & 50000 & 100000 & Drop Umur 6 hari (D6) \\
\hline & 30 & 1 & 300000 & 300000 & Drop Umur 8 hari (D8) \\
\hline
\end{tabular}

Dari tabel diatas terlihat bahwa penebaran telur bulan Okotber menghasilkan jumlah panen benih tertinggi yaitu sebanyak 1020 ekor (SR 0,51 \%). Hasil ini bila dibandingkan dengan hasil yang diperoleh Amiruddin $d k k$., (2011) masih lebih baik. Amiruddin $d k k$., (2011)memperoleh benih sebanyak 867 ekor lebih sedikit dari hasil yang diperoleh pada kegiatan ini. Dengan demikian penggunaan alga gel (natadechlorella) dapat digunakan dalam kegiatan pemeliharaan larva kerapu sunu, apalagi pada saat kondisi hujan dimana ketersediaan pakan alami (fitoplanton) terbatas.

\section{Parameter Kualitas Air Bak Pemeliharaan Larva}

Secara umum parameter kualitas air (suhu, salinitas, $\mathrm{DO}$ dan $\mathrm{pH}$ ) dalam bak pemeliharaan larva masih sesuai dengan parameter kualitas air dalam pemeliharaan larva kerapu sunu. Jelasnya dapat dilihat pada tabel dibawah ini :

Tabel 4. Kisaran Parameter Kualitas Air Bak Larva Ikan Kerapu Sunu (P. leopardus) Dari Bulan Januari Desember 2012

\begin{tabular}{lcccc}
\hline \multirow{2}{*}{ Bulan } & \multicolumn{4}{c}{ Parameter Kualitas Air } \\
\cline { 2 - 5 } & Suhu & Salinitas & DO & pH \\
\cline { 2 - 5 } & $\left(\mathbf{(}^{\circ} \mathbf{C}\right)$ & $(\mathbf{\%})$ & $(\mathbf{p p m})$ & \\
\hline Oktober & 28,0 & 31,6 & 4,42 & 8,20 \\
Nopember & 28,5 & 32,0 & 4,77 & 8,12 \\
Desember & 29,4 & 32,8 & 4,72 & 8,23 \\
\hline
\end{tabular}

Berdasarkan tabel di atas, terlihat bahwa selama kegiatan pemelharaan larva berlangsung, rata-rata parameter suhu berkisar antara $28,0-29,5^{\circ} \mathrm{C}$; Salinitas berkisar antara 31,6-32,8 ppt ; DO berkisar antara 4,42 - 4,77 ppm dan $\mathrm{pH}$ berkisar antara 8,12 - 8,23. Kisaran parameter suhu, salinitas, $\mathrm{pH}$ dan DO sebagaimana yang terlihat pada tabel diatas semua masih dalam batas kisaran yang dapat ditolerir oleh larva kerapu sunu yang dipelihara. 
Irawati dan Damaris Payung. Penggunaan Alga Gel (Nataclhorella) Dalam Larva Rearing Untuk Meningkatkan Survival Rate Benih Kerapu Sunu (Plectropomus leopardus)

\section{Kesimpulan}

\section{KESIMPULAN DAN SARAN}

- Laju fertilisasi (FR) dan Laju Penetasan (HR) telur pada setiap siklus pemijahan induk tergolong cukup tinggi dengan FR 75-80\% dan HR 80-90\%.

- Penggunaan Natadechlorella menghasilkan benih sebanyak 1020 ekor dengan SR 0,51\%.

\section{Saran}

- Penerapan penggunaan Natadechlorella perlu dilakukan pada setiap siklus pemijahan dan bukan hanya pada bak pemeliharaan larva namun juga dapat digunakan sebagai pengkayaan pada kultur rotifer.

\section{DAFTAR PUSTAKA}

Anonimous, 2004. Pembenihan Ikan Kerapu. Balai Budidaya Laut Lampung.Direktorat Jenderal Perikanan Budidaya. Departemen Kelautan dan Perikanan. Lampung.

Anonimous, 2004. Petunjuk Teknis Budidaya Laut Ikan Kerapu, Ditjen Perikanan Budidaya, Direktorat Pembudidayaan. Jakarta.

Blaxter H.S., 1969. Development of egg and larvae. P: 184-190. In hoar and Randall (eds), Fish Physiology Vol III, Academic Press Inc

Cholik F., Jagatraya AG., Poernomo, Jauzi A., 2005. Akuakultur Tumpuan Harapan Masa Depan Bangsa., Masyarakat Perikanan Indonesia dan Taman Akuarium air Tawar. Jakarta.

Geffen, A.J., Fox, C.J., and Nash, R.D.M. 2006. Temperature-dependent development rates of cod, Gadus morhua eggs. Journal of Fish Biology: 69, 1060-1080.

Ismi S., 2007. Produksi Kerapu Sunu (Plectropomus leopardus) Di Hatchery Skala Rumah Tangga. Balai Besar Riset Perikanan Budidaya Laut. Departemen Kelautan dan Perikanan, Bali.

Laevastu T. dan L.H. Murray. 1981. Fisheries Oceanography and Ecology. Fishing New Book Ltd. England.

Suwirya, K. A. Prijono, A. Hanafi, . Andamari, R. Melianawati, M. Marzuqi, K. Sugama, N. A. Giri. 2006. Pedoman Teknis Pembenihan Ikan Kerapu Sunu (Plectropomus leopardus). Pusat Riset Perikanan Budidaya. Badan Riset Perikanan dan Kelautan, Bali.

Tang, U.M dan R. Affandi, 2000. Biologi Reproduksi Ikan. Institute Pertanian Bogor

Watanabe T. 1988. Fish nutrition and marine culture. JICA. Text Book. The General Aquaculture Course. Department of Aquatic Bioscience 